\title{
Potential for change in the food industry
}

\section{By A. G. WARD, Procter Department of Food and Leather Science, University of Leeds, Leeds LS2 9 fT}

The food industry in the United Kingdom is still in private ownership. It is operated in order to make a profit as a necessary condition for the conduct of its business. This business is to provide preserved and prepared food for the United Kingdom population and for export. The food industry includes multi-national firms, a number of which have parent companies and research facilities in the USA. The influence of the US food and food machinery industries on United Kingdom food is, however, more extensive than these direct contacts provide. In looking to the future, it is reasonable to conclude that at least the bulk of the food industry will remain, as at present, in private ownership during the period with which I am concerned. So it will continue to direct its efforts to activities likely to be profitable, as one of the constraints within which it must be carried on.

The preceding papers at this symposium have indicated many of the probable circumstances and some further constraints within which the United Kindom food industry will find itself operating in the future. Brief reference to some of these is needed before more technical aspects are discussed.

\section{Future conditions affecting the provision of processed foods}

In a period of sharply-rising prices, the public is particularly conscious of price changes in commodities purchased regularly. The effect is strongest for those goods the continued purchase of which is essential for normal domestic life. Of these, food clearly dominates the concern of those involved in running homes. Indeed the prices of food and drink are of central interest for almost the whole population. So it has come about that governments, in the attempt to minimize the impact of inflation on consumers, have applied to foodstuffs schemes for limiting price rises with greater rigour than for most other commodities. The effect on the supply of fresh foods of too rigidly applied limitations becomes rapidly obvious, since it results in reduction by farmers of the extent of crops planted or of animals reared. This outcome is readily presented to and comprehended by politicians, the Press and the public. So it has been the food-processing industry that has had to bear the main impact of food price control. The consequences are slower to be detected in an industrial operation. They begin to show themselves by a diminution of innovative research, reduced product development and reduced process development except where directly linked with cost saving, reduced plant upgrading and replacement and in the longer term by the consequences of such 
reductions. In particular, the potential for change is limited. It is also channelled into areas of only marginal long-term value, e.g. the substitution of cheaper raw materials and closer control of any variability of for example composition and weight, to allow a lower mean value to be used as the working figure. So future development is sacrificed to immediate expediency, not through the shortsightedness of industry but as a result of misguided public and political pressure.

\section{Changes in catering and domestic cooking}

In the United Kingdom the two most likely continuing changes which will affect the provision of food are, first, a sharp increase in the proportion which will be consumed through catering outlets (including 'take-away') as compared with that prepared and cooked in the home. Secondly, and related to this, is the greater use of ready-prepared foods in home meal preparation. The reasons underlying these changes would take too long to explore here but the trends are already well marked and show every sign of continuing. In the USA catering has already taken over a much higher proportion of food preparation and service than in Europe and the forecasts are for further inroads of caterers into food provision in the next Io years. It by no means follows that all the forms of food currently used in the home, where the cost of domestic work is rarely evaluated, are those best adapted for catering use, where equal pay and other measures have increased wage costs relative to other costs and even relative to wage costs in other industries. While in the past many food manufacturing firms have provided special catering packs, usually either larger or of poorer quality than the corresponding domestic packs, only limited advantage has been taken by manufacturers and caterers of the chance to eliminate costly catering labour by means of efficient preparation and processing under factory conditions. The main advances so far have been in partially-prepared vegetables, canned and frozen foods. These same advances are equally applicable in providing ready-prepared foods in the home. In particular the widespread installation of deep-freeze cabinets has permitted greater exploitation of the potential provided by frozen fresh and precooked foods.

\section{Animal v. vegetable foods}

The consumption of animal foods, meat, fish, eggs, milk and their products is known to be costly in terms of land utilization, of energy employed and of labour, not least because modern intensive husbandry is only possible with the support of crop production of cereal, grains, soya-bean and other oilseed residues and roots to provide food for animals. The vegetable crops could be used more economically as human food, by direct consumption. Some types of farmland as on hill farms can perhaps be most economically used for animal production, at least for the foreseeable future. It is evident that animal foods will continue to be eaten extensively in the United Kingdom, despite high prices, until the time comes when other foods are able to compete with and replace them, in terms of being enjoyable to eat and at the same time cheaper. 


\section{Other suitable foods}

Some imported raw materials, such as coffee, cocoa beans and tea have risen disproportionately in price due to excess demand, resulting in part from poor crops. High prices are now required by developing countries to provide their foreign currency. There are therefore opportunities to develop substitutes for such costly foods, especially since their direct nutritional significance is small. Any substitute needs to be sufficiently closely matched to the product to be replaced to fulfil the same needs. Some other foods, such as the banana, have also little nutritional contribution to make to the United Kingdom diet except in variety and so could well disappear from the United Kindom market if economic conditions, especially the balance of payments, became more adverse. In the Second World War the banana ceased to be available in the United Kingdom without noticeable loss and a generation gave it a mixed greeting when it returned at the end of the war.

\section{Fish and fish products}

Fish is the only major food still provided by hunting. As such it is unaffected so far by deliberate breeding programmes. It is, however, costly in energy if modern long-distance trawlers, freezing at sea and frozen storage and distribution are used. Newly-fished species, such as blue whiting (Micromesistius poutassou) (Torry Research Station, 1975), and rigorous conservation of stocks may continue to enable fish to be eaten in the United Kingdom and used by the food-processing industry on a substantial scale. The apparently attractive fish-farm concept offers the chance to breed and raise fish in the same way that farm animals have been selected and bred. But this throws away the main asset of fish and fishing, the zero cost of production up to the point of catching. In fish-farming, food must be supplied, the fish bred and confined and diseases avoided. It is not therefore surprising that only high cost fish, trout (Salmo trutta), turbot (Scophthalamus maximus), etc., appear likely to be economic in fish-farms and the food industry is unlikely to find them an important raw material.

\section{Relation with nutrition}

For most of human prehistory and history, the mass of mankind has had a primary preoccupation with securing sufficient food to eat to comply with energy needs. This was essentially true in the United Kingdom until very recently. Choice of foods was based largely on price. For adults today those able to meet their food energy needs fulfil also most, if not all, of their other nutrient requirements. Until the $193^{\circ}$ 's, attempts to guide at all closely the national diet from the then existing nutritional knowledge would have been quite as likely to produce a disaster as to improve the situation. By the Second World War much of the knowledge required to prevent deficiency diseases had been worked out (Drummond \& Wilbraham, 1958) and this information was brilliantly applied by Sir Jack Drummond to feed the nation and indeed to raise the over-all standard of nutrition at a time when every imported ship-load of food had to compete with armaments. The knowledge 
needed to avoid deficiencies has been consolidated and extended since that time. The more far-reaching concept, the specification of nutritional needs for positive health, has made only limited progress and any claims in this respect need rigorous criticism. Governments have rightly been cautious of imposing rules, based on current nutritional views of optimum diets, on the foods made available to the public. Only where nutrient additions may remedy known or possible deficiencies of essential nutrients has legislation been continued or enacted. Indeed since the prevalent nutritional disorder today is excessive consumption, governments would be reluctant to act even if nutritionists knew what to recommend! Despite continuing scepticism about the precise causal links between diet and health, governments may be forced by public pressure to legislate sometimes on incomplete scientific evidence as, indeed, has happened in the past in controlling the use of some additives.

So it is by no means clear what nutritional guide-lines, if any, will be arrived at to guide the food industry's development of foods, nor the form of any legislation enacted to implement them.

\section{Nero foods}

Currently the development of replacements for existing foods, or the creation of new foods, from cheaper and perhaps more freely-available raw materials has the general guidance of a ruling by the Committee on Medical Aspects of Food Policy (December, 1972) (Food Standards Committee, 1975). This says 'any substance promoted as a replacement or as an alternative to a natural food should be the nutritional equivalent in all but unimportant aspects of the natural food which it would simulate'. This ruling is widely accepted as reasonable, dispute being mainly concerned with the interpretation of 'all but unimportant aspects' in relation to food composition, place in the diet and the extent to which dietary needs for nutrients are adequately provided by other foods.

\section{The potential within the food industry for change}

The main processes of food preservation, drying, freezing, chilling, heating, osmotic reduction of water activity, acidifying and use of preservatives have long empirical histories and have only recently been subjected to scientific study. The research effort or even the combined research and development ( $R$ and $D)$ effort of the food industry is small compared with its turnover or the aggregate value added. The $R$ and $D$ carried out within the industry itself is concentrated among a very few firms. Only a handful of food firms carry out any long-range investigations and some of the more startling developments with great potential, e.g. microbial protein production from methane, methanol or alkanes, or from waste products, have been researched and developed largely outside the food industry.

While limited $R$ and $D$ resources are characteristic of industries employing mainly traditional basic techniques with natural-product raw materials, the financial limitations on the food industry resulting from government action make it unlikely that most food firms will allocate $R$ and $D$ resources which are commensurate with the complex problems which food research poses. Even in the 
USA few really novel developments have come from food research. Of the two discoveries which showed promise in the 1950's, freeze-drying has come into its own for a few rather-high-cost products, such as instant coffee, where its fluid state before drying makes the process simpler and avoids the damage freezing and drying does to such foods as fish and meat. The second discovery, irradiation, seems unlikely to be employed for its original objective, food sterilization, at all widely and its main potential is proving to be where low radiation doses have important effects (insect disinfestation of grain, sprout-inhibition in potatoes).

To make more effective use of raw materials of plant origin which are available at low cost, it is necessary to be able to prepare new products which, in addition to being adequate nutritionally, combine (1) attractive shape and appearance; (2) acceptable textural characteristics which survive or are suitably modified during cooking; (3) flavours which are adequate both in immediate impact during chewing and which persist until the food is swallowed. It is a happy compounding of all three characteristics which gives desirable eating qualities to the apple, meat and eggs as well as to such man-modified foods as bread, cheese and the omelette. In a world where many have insufficient food, a cheap, nutritionally-satisfactory new food may be able to make its way initially, despite some defects. Even in such circumstances, as practical experience has shown, foods which do not fit into conventional eating patterns may be rejected even by the hungry. In a well-fed country, even when food is becoming dearer, the task is more difficult and a real appeal to the senses must be attained. Custom and habit in choosing food die hard, even with a threat of food shortage. Under conditions of shortage, however, criticism becomes less keen. The consumption by the richer inhabitants of Paris of the zoo animals in the siege during the Franco-Prussian war is one example. The fortitude and ingenuity of the British civilian population when presented with dried egg at a late stage of the Second World War is another, which some will remember.

The development and manufacture of novel foods to give satisfaction to the consumer in all respects, as well as the modification of existing foods to make them palatable, involves many disciplines spanning the whole of food science and extending beyond its normal bounds into sensory physiology, psychology and the sociology of food-consumption patterns. The recent attempts by many companies to prepare novel foods, using as foundation the protein-rich residues from vegetable oils and fats manufacture, have shown how little is known of what might be called 'molecular cookery'. The framework underlying the texture of most solid foods is made up of protein and carbohydrate macromolecules, sometimes interleaved by lipid layers, with water playing a structural and lubricating role. Foods have exploited biological structures derived from their raw materials, modifying them by cooking, mixing and fermentation. In very few instances have the relations between structure, properties and consumer acceptance been completely worked out.

The present forms of vegetable-protein foods (Food Standards Committee, 1975) utilize, in one process, the extrusion of a dough based on either defatted 
soya-bean flour or on soya-bean concentrate. In a second process, soya-bean isolate is spun into fibres. Both techniques attempt to produce a texture to simulate that of meat. Success is limited and the method of spinning soya-bean isolate increases costs to a level which reduces its attractions. The techniques are largely empirical. A more basic approach to the creation of new food textures and to understanding the origins of existing textures will require research into: (I) the various ways in which protein molecules (and/or carbohydrates) can create structures in foods. The stability of the structures during preservation and cooking or their desirable modification by these processes must be included, together with the influence of other components on the structures; (2) the experimental measurement and theoretical interpretation of the mechanical behaviour of the foods which result from these structures and the development of test methods capable of monitoring the key properties; (3) the relation between the instrumental properties given in (2) and those assessable by sensory methods; (4) the understanding of the physiology and psychology of sensory evaluation and the influence of social factors on sensory judgement and so on food choice.

Parallel problems of comparable significance exist in connexion with flavours. For colours, where basic understanding is greater, perhaps the limitations imposed by the need to demonstrate safety for human consumption have the greatest influence on what is done. The high cost of carrying out the formidable battery of toxicological tests required limits the provision of new colours to replace old, or to extend the range. Indeed it should be commented that, unless care is taken, the whole complex structure of modern food legislation may act as a powerful brake on the development of the new foods which may be needed in the r 980 and 19905 .

There is no room here to discuss many interesting actual and potential developing areas such as immobilized enzymes, fermentation procedures, membrane-separation methods and practical advances which might follow from a better understanding of the changes occurring in the freezing and thawing of most foods and also in drying. There remains however the question as to how the United Kingdom industry will be able to carry out the necessary $R$ and $D$, taking into account that there is a public interest in ensuring that nutritionally-adequate food, of the quantity and quality required for the United Kingdom population, will be available in the future.

\section{$R$ and $D$ resources}

The resources for food $R$ and $D$ available within the United Kingdom are divided between (1) the food industry and its suppliers; (2) laboratories operated in a co-operative way, or by direct sponsoring, in the research associations, to which government makes a contribution by sponsoring appropriate subjects; (3) laboratories provided with government funds in Agricultural Research Council (ARC) institutes, the resources of which come partly from the ARC's own funds and partly through the Ministry of Agriculture, Fisheries and Food (MAFF) and the Department of Agriculture and Fisheries for Scotland. To these must be added MAFF's own research stations; (4) the university departments of food science and 
food technology, which are largely supported by government funds, but also employ grants from industry. The early, largely satisfactory, relation between industry-supported and government-supported research, epitomized in the activities of the Food Investigation Board after the First World War (Ward, 1976), was impaired by the destruction of the Board in the late $1950 \mathrm{os}$. The recent attempt by the Joint Consultative Organization (JCO) for Research and Development in Agriculture and Food and in particular by the JCO Food Science and Technology Board to rebuild an interlinked approach for industry- and government-sponsored $R$ and $D$ still faces many difficulties. Not least of these is the disproportionately low level of resources provided for food $R$ and $D$ by government. The scale of support prevents any significant development work being attempted and also minimizes research into processes and plant on the full-scale or even using the 'pilot' plant. The Board's Reports (Ministry of Agriculture, Fisheries and Food, 1975, 1977) should be consulted to see the directions in which government support of research is regarded as desirable and the need these create for additional funding.

Whether by direct $R$ and $D$ within industry or by government-supported research or by both closely integrated, the future development of the food industry will be dependent on the resources available for $R$ and $D$. In the absence of sufficient $R$ and $D$ the United Kingdom industry will trail behind industries elsewhere and will develop technologically only as a result of adopting changes already in operation in other countries.

\section{REFERENCES}

Drummond, J. C. \& Wilbraham, A. (1958). The Englishman's Food. Revised D. Hollingsworth. London: Cape.

Food Standards Committee (1975). Report on Novel Protein Foods. London: HM Stationery Office.

Ministry of Agriculture, Fisheries and Food (1975). Second Report of the Boards of the Joint Consultative Organisation for Research and Development in Agriculture and Food. London: HM Stationery Office.

Ministry of Agriculture, Fisheries and Food (1977). Third Report. Food Science and Technology Board, foint Consultative Organisation for Research and Development in Agriculture and Food. London: Ministry of Agriculture, Fisheries and Food.

Torry Research Station (1975). Annual Report. London: Ministry of Agriculture, Fisheries and Food.

Ward, A. G. (1976). Chemy Ind. p. 1011. 